Article

\title{
Auxiliary Power Supply System for Electric Power Steering (EPS) and High-Heat-Resistant Lithium-Ion Capacitor $^{+}$
}

\author{
Takumi Mio ${ }^{1, *(1)}$, Yukihiro Komatsubara ${ }^{1}$, Naoki Ohmi ${ }^{1}$, Yusuke Kimoto ${ }^{1}$, Kentaro Iizuka ${ }^{1}$, \\ Tomoki Suganuma ${ }^{1}$, Shun Maruyama ${ }^{1}$, Toyoki Sugiyama ${ }^{2}$, Fumihiko Sato ${ }^{2, *}$, \\ Satoshi Shinoda ${ }^{2}$, Tokuaki Hibino ${ }^{2}$ and Koji Nishi ${ }^{1}$ \\ 1 Power Storage Device Dev. Group, BR Electrical Power Storage Device Business Dept., JTEKT Corporation \\ 1-7 Kitajizouyama, Noda-cho, Kariya, Aichi 448-0803, Japan; yukihiro_komatsubara@jtekt.co.jp (Y.K.); \\ naoki_ohmi@jtekt.co.jp (N.O.); yusuke_kimoto@jtekt.co.jp (Y.K.); kentaro_iizuka@jtekt.co.jp (K.I.); \\ tomoyuki_suganuma@jtekt.co.jp (T.S.); syun_maruyama@jtekt.co.jp (S.M.); koji_nishi@jtekt.co.jp (K.N.) \\ 2 Power Supply System Dev. Group, BR Electrical Power Storage Device Business Dept., JTEKT Corporation \\ 1-7 Kitajizouyama, Noda-cho, Kariya, Aichi 448-0803, Japan; toyoki_sugiyama@jtekt.co.jp (T.S.); \\ satoshi_shinoda@jtekt.co.jp (S.S.); tokuaki_hibino@jtekt.co.jp (T.H.) \\ * Correspondence: takumi_mio@jtekt.co.jp (T.M.); fumihiko_satou@jtekt.co.jp (F.S.) \\ + Presented at EVS 31 \& EVTeC 2018, Kobe, Japan, 1-3 October 2018
}

Received: 19 April 2019; Accepted: 18 May 2019; Published: 22 May 2019

\begin{abstract}
Advanced Driver Assistance System (ADAS) and Automated Driving (AD) are the two major topics for the current and next generations of vehicles. To realize them in full-size vehicles equipped with a $12 \mathrm{~V}$ power supply, the need for electric power steering (EPS) is increasing. Currently, the steering system of full-size vehicles is equipped with hydraulic power steering due to electric power shortage. An auxiliary power supply system using a lithium-ion capacitor was developed in order to solve the concern. In addition, to mount the system in the vehicle with no cooling-heating equipment, development of expanding the operating temperature range of the lithium-ion capacitor was conducted. Several improvements have made the capacitor operate stably in high-temperature environments above $100^{\circ} \mathrm{C}$.
\end{abstract}

Keywords: electric power steering; temporary power boost; redundant power supply; lithium-ion capacitor

\section{Introduction}

Advanced Driver Assistance System (ADAS) and Automated Driving (AD) are the two major topics for the current and next generations of vehicles. According to the roadmap issued by the Prime Minister's Office in Japan, Level 4 of the AD level defined by the SAE International in J30162 (September 2016) will be realized around 2025 in limited scenes such as expressways and highways [1,2]. AD functions take over the longitudinal and lateral guidance of the vehicle and must be fail-operational in case of any failure [3-5]. Therefore, it is also essential to improve functional safety in electric power steering (EPS) to protect SAE Level 3 or higher from power failure during driving [6,7].

To realize ADAS and AD functions in full-size vehicles equipped with a $12 \mathrm{~V}$ power supply, the need for EPS is increasing. Currently, the steering system of full-size vehicles is equipped with hydraulic power steering due to electric power shortage. In order to steer a 3.5-ton class full-size vehicle, up to about $18 \mathrm{kN}$ of steering rack force is required. Assuming that the overall efficiency of the EPS, including the ECU, motor, and gears, is approximately $50 \%$, the electric power required to output the steering force is about $2000 \mathrm{~W}$. If the necessary power is supplied from a $12 \mathrm{~V}$ power supply, 
about $170 \mathrm{~A}$ is required, but the current supplied to the EPS is up to $120 \mathrm{~A}$, so the power demand of EPS cannot be satisfied. $12 \mathrm{~V}$ power supply can only drive EPS for vehicles weighing less than 3 tons (about $12 \mathrm{kN}$ rack force).

The shortage for the electric power required by the EPS must be compensated by the driver's steering force. This is manifested as an "EPS torque-assist delay phenomenon" in which the steering wheel suddenly becomes heavy during abrupt steering or stationary steering. So, in order to install EPS to full-size vehicles equipped with a $12 \mathrm{~V}$ power supply, torque-assist delay phenomenon must be solved.

In recent years, $48 \mathrm{~V}$ mild-hybrid vehicles have been launched, mainly in Europe and the United States, but $48 \mathrm{~V}$ is a drive system power source only, and auxiliary electronics components are still conventional $12 \mathrm{~V}$ [8]. Since EPS belongs to auxiliary electronics components, the electric power shortage cannot be resolved. It will take a long time for the overall voltage of the vehicle to rise.

In addition, when installing EPS in a full-size vehicle, it is necessary to consider the steering force change at the time of temporary power loss. There is a possibility that driving cannot be continued if EPS assist is lost. Even while the torque-assist delay phenomenon occurs, a part of the steering force necessary for steering a full-size vehicle is output from the EPS, but in the situation of a power supply failure, all the torque-assist force is lost. It is impossible to satisfy the steering force only with the power of the driver.

Aside from the realization of ADAS and AD, there are benefits to introducing EPS to full-size vehicles. A typical point is that it is environmentally friendly. The conventional hydraulic power steering uses the driving force of the engine to constantly power the hydraulic pump in order to generate hydraulic power. This creates excess burden on the engine and is one of the reasons for high fuel consumption. The EPS system operates the motor only during steering, therefore reducing the load on the engine and improving fuel consumption by approximately $2.5 \%$ [9].

Consequently, JTEKT worked on development of the auxiliary power supply system for EPS with the following features [10,11]:

1. Elimination of the torque-assist delay during abrupt steering and stationary steering

2. Peak cut of the electric power consumption during abrupt steering and stationary steering

3. Redundant power supply in case of $12 \mathrm{~V}$ power supply failure

\section{EPS Electric Power Consumption}

First, Figure 1 shows the result of maximum electric power consumption of various electrical components of a vehicle. The electric power consumption of the EPS system during abrupt steering is larger than that of the air conditioner and headlights. On the other hand, the electric power consumption of the EPS during straight-line driving is only $3 \%$ of stationary steering.

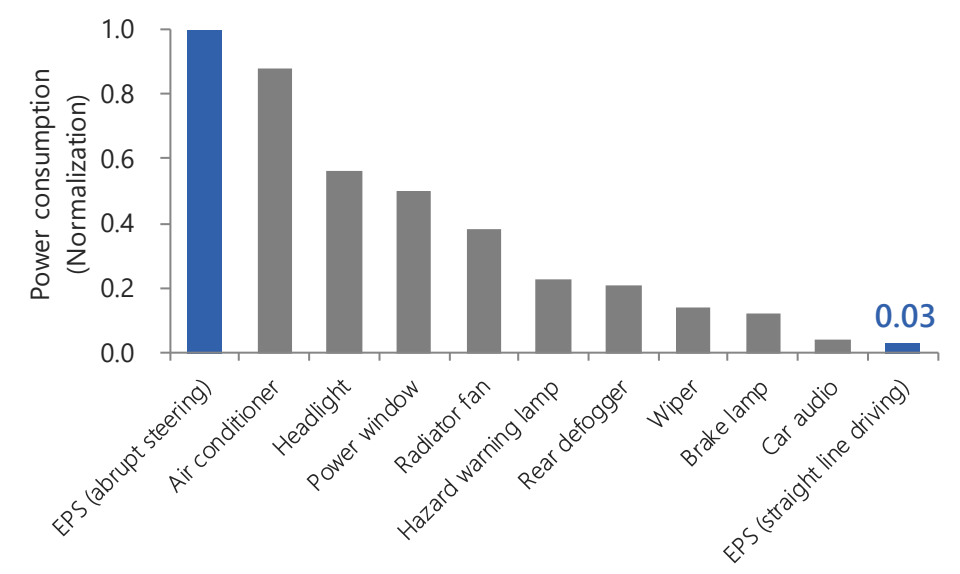

Figure 1. Measuring result of maximum electric power consumption of various electrical components of vehicle. 
Next, Figure 2 shows the power consumption during abrupt steering of a full-size vehicle. The $12 \mathrm{~V}$ power supply temporarily cannot satisfy the EPS electric power demand (A, B). In other words, to install EPS in a full-size vehicle, it is only necessary to eliminate the several seconds of power shortage that occurs during abrupt steering. The reinforcement of the whole $12 \mathrm{~V}$ power supply is not an optimal solution. For the above reasons, development of an auxiliary power supply system has started.

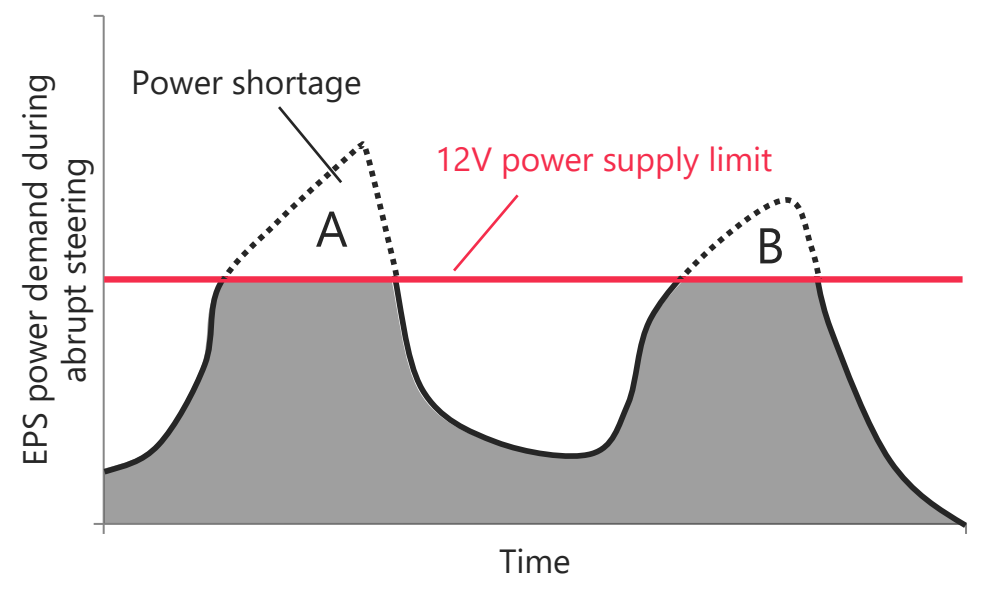

Figure 2. Electric power consumption of EPS during abrupt steering.

\section{The Configuration of Auxiliary Power Supply System for EPS}

\subsection{System Summary}

Figure 3 shows the configuration of the auxiliary power supply system for EPS. The system consists of a charge-discharge controller and electrical power storage device. It is installed between the $12 \mathrm{~V}$ power supply and the EPS. The lithium-ion capacitor was adopted as a power storage device given its rapid charge-discharge characteristics, cycle life, safeness, operating voltage, and volume energy density.

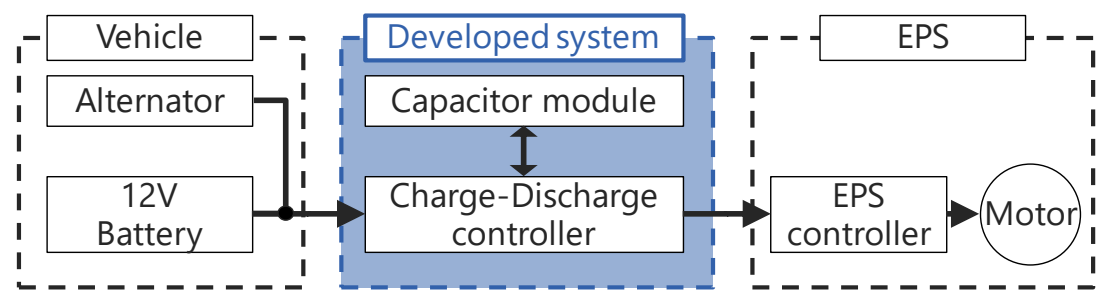

Figure 3. Configuration of auxiliary power supply system for EPS.

\subsection{Block Diagram and Control Method, Design of Capacitance of Capacitor}

Figure 4 shows a block diagram of the charge-discharge system. The system possesses a charge circuit [D] and a discharge circuit [E]. The central processing unit (CPU) of the charge-discharge controller monitors the $12 \mathrm{~V}$ power supply and EPS. The CPU controls the discharge circuit to boost the power supply voltage by connecting the lithium-ion capacitor in series with the $12 \mathrm{~V}$ power supply (x) when the EPS requires energy that is beyond the upper limit of the $12 \mathrm{~V}$ power supply. When the lithium-ion capacitor discharges and the cell voltage drops, the CPU controls the charge circuit to recharge the lithium-ion capacitor from the $12 \mathrm{~V}$ power supply (y).

As the number of lithium-ion capacitors connected in series is increased, the system output increases. Generally, a $12 \mathrm{~V}$ electronic circuit board has a performance of $24 \mathrm{~V}$ withstand voltage. Even if the capacitor is connected in series to the $12 \mathrm{~V}$ power supply and boosted, no problem occurs if the voltage is up to about $20 \mathrm{~V}$. 
Furthermore, because the lithium-ion capacitor has an average voltage of $3 \mathrm{~V} /$ cell, a $12 \mathrm{~V}$ power supply can be obtained by connecting four capacitors in series. In this configuration, it is suitable as a backup power supply during a $12 \mathrm{~V}$ power supply failure. It contributes to the realization of $\mathrm{AD}$ Level 4 that requires complete failure operation of EPS including power supply failure [12,13].

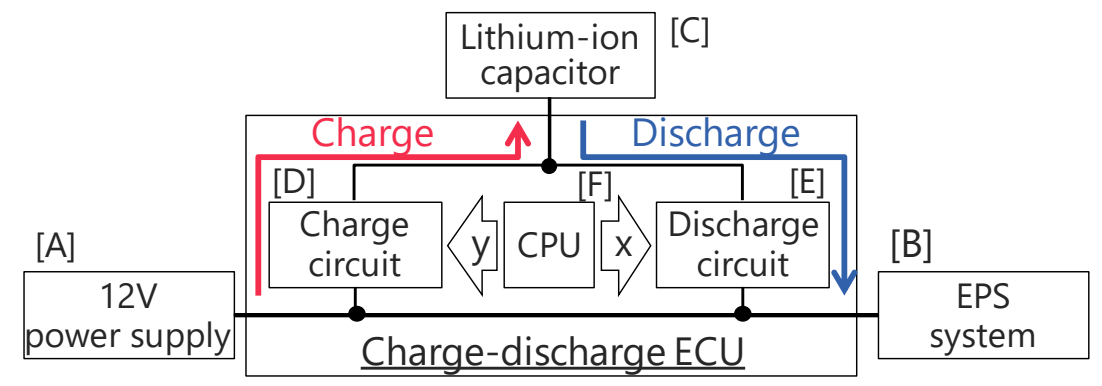

Figure 4. Charge-discharge system for EPS block diagram.

Detailed circuit operation is shown in Figure 5. If the power consumption of the EPS is low, such as for straight-line driving, the FETs 1 and 2 are closed and the EPS is operated only by the $12 \mathrm{~V}$ power supply. When the EPS requires a large amount of power, such as for abrupt steering or stationary steering, FETs 1 and 3 are closed, and the lithium-ion capacitor is connected in series with the $12 \mathrm{~V}$ power supply. After the system operates and the capacitor voltage drops, the lithium-ion capacitor is recharged using FETs 4 and 5 and the coil. Recharging starts when the electric power demand of the EPS falls below the $12 \mathrm{~V}$ power supply limit. If a power supply failure occurs, the EPS is driven by the electric power of the lithium-ion capacitor by closing FETs 3 and 5. Also, if something goes wrong with the circuit, FET 6 is closed and the EPS is driven with the bypass circuit.

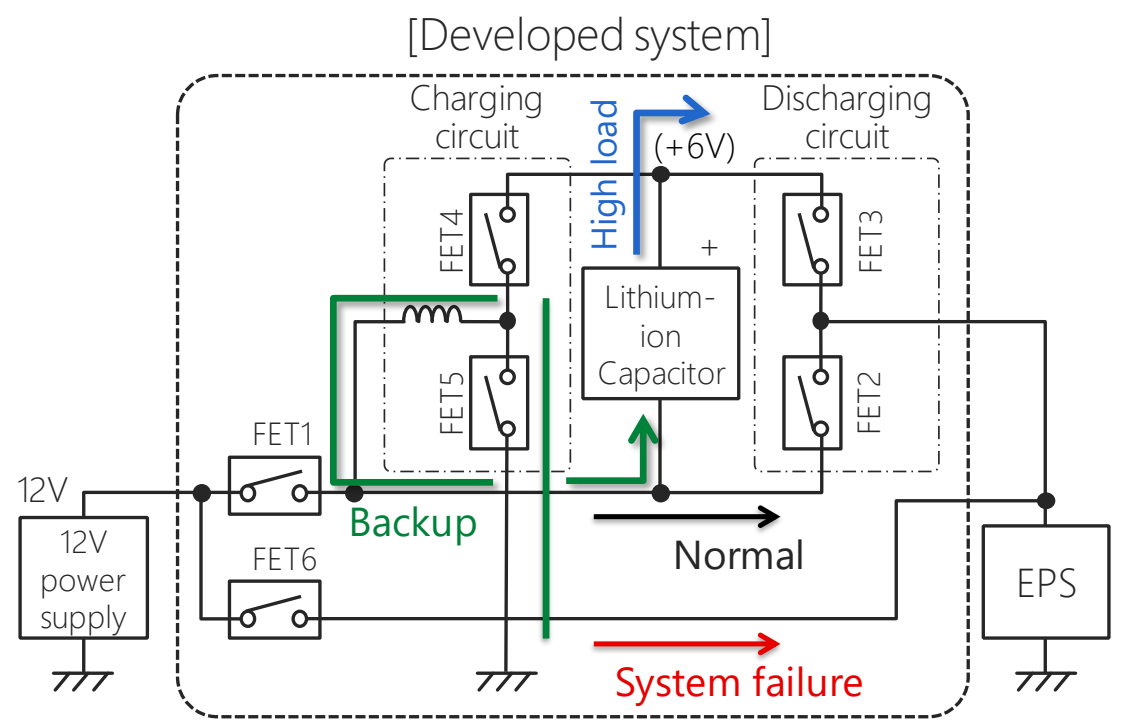

Figure 5. Circuit operation of charge/discharge controller.

The energy amount design of the lithium-ion capacitor required by the system is explained using the power waveform when performing a continuous stationary steering test on a 3.5-ton class full-size vehicle shown in Figure 6. 


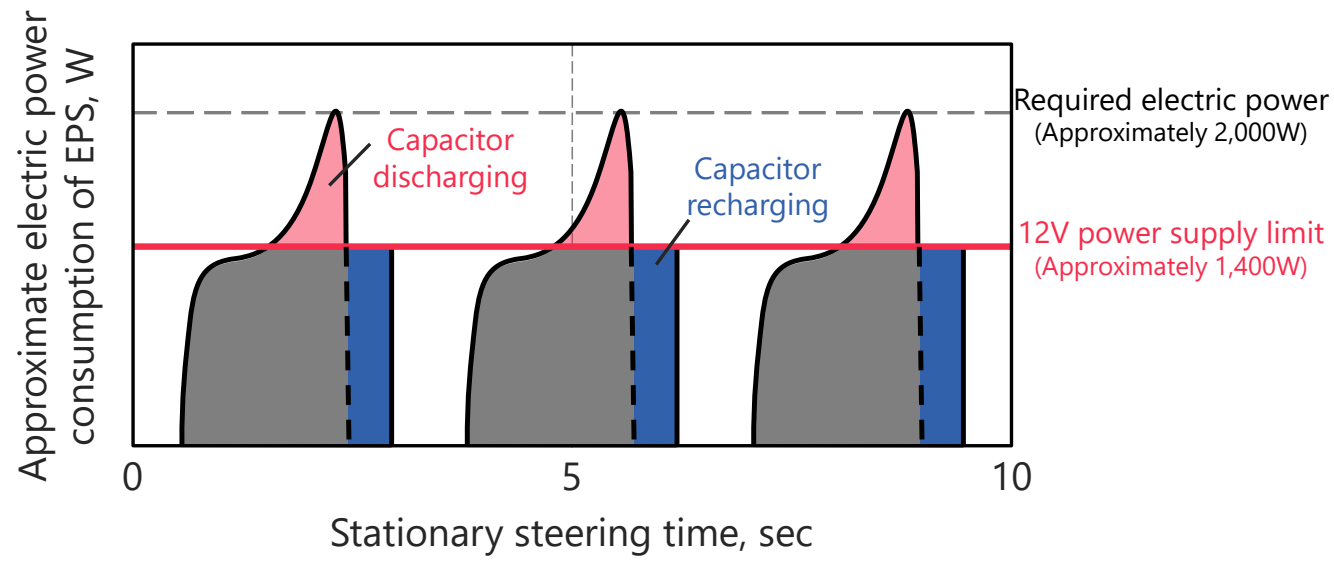

Figure 6. Electric power waveform during continuous stationary steering test of 3.5-ton class full-size vehicle (the steering speed is $600 \%$ s).

As described in the introduction, the $12 \mathrm{~V}$ power supply limit is approximately $1400 \mathrm{~W}$, and the power required for 3.5-ton class stationary is approximately $2000 \mathrm{~W}$. As the steering angle increases, the electric power demand of EPS increases. In the power waveform, the integrated value of a region (red area) in which the electric power demand of EPS exceeds the $12 \mathrm{~V}$ power supply limit is the required energy amount of the lithium-ion capacitor per 1 time of stationary steering. Assuming that the power shortage region (red area) is approximated as a triangle and the power assist time is approximately $1 \mathrm{~s}$, the required energy amount of the lithium-ion capacitor is about $300 \mathrm{~J}$. The required energy amount of the system is obtained by multiplying the number of times to guarantee the stationary steering, and as shown in the blue area of Figure 6, it can be reduced by controlling to recharge as soon as the power demand of EPS falls below the $12 \mathrm{~V}$ power supply limit.

The system can be built with a very small amount of energy and number of cells, but since it is necessary to supply a large current of up to $120 \mathrm{~A}$, the system can only be designed with capacitors. When building the system with a battery, it is necessary to have a very large capacity, most of which is not used.

\section{Mechanism of High Power Output}

The torque-assist delay phenomenon that occurs at the time of abrupt steering in EPS using brushless DC motor is described below with reference to the motor rotation speed and torque characteristic diagram (N-T characteristic diagram) shown in Figure 7.

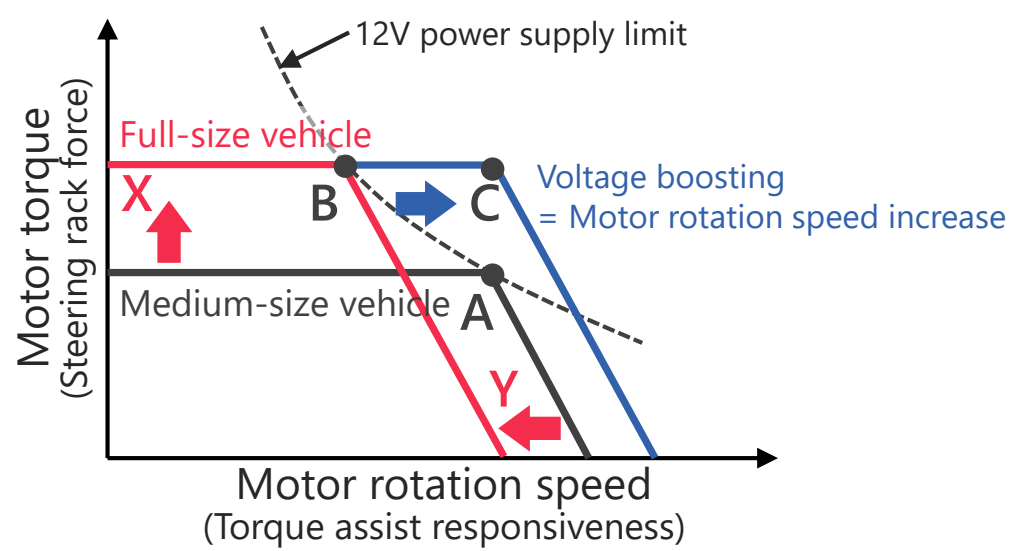

Figure 7. Motor rotation speed and torque characteristic diagram (N-T characteristic diagram of brushless DC motor). 
The N-T characteristic when the torque command value is constant is indicated by the solid line in Figure 7. The dashed line is the upper limit of the electric power that can be supplied from the $12 \mathrm{~V}$ power supply.

When the motor is rotated with the torque command value set to a certain value, the rotation speed at the point (rated point $\mathrm{A}$ ) intersecting the dashed line of electric power is the maximum rotation speed at which the commanded torque can be outputted.

If the command torque is increased to output the steering rack force required for a full-size vehicle, the rated point moves on the broken line of electric power from rated point $A$ to rated point $B$ as shown in Figure 7 " $X$ ". The maximum value of motor rotation speed that can output the command torque decreases as shown in Figure 7 " $Y$ ".

The output torque decreases in the region above this rotation speed. Since the steering force of the driver increases as EPS torque assist decreases, abrupt steering causes the steering wheel to become heavy, resulting in "torque-assist delay".

When the capacitor voltage is added to the $12 \mathrm{~V}$ power supply using the auxiliary power supply system, the rated point moves from B to C, and motor rotation speed can be increased while maintaining the command torque. This is the same as EPS assist torque reinforcement under the abrupt steering situation.

\section{Actual Vehicle Evaluation}

\section{Testing Method}

The steering system of a full-size SUV (car weight 3.5-ton class) equipped with hydraulic power steering was replaced with rack assist type EPS equipped with a $600 \mathrm{~W}$ brushless DC motor. It could output the steering rack force up to $18 \mathrm{kN}$. The torque assist responsiveness of EPS to steering speed was evaluated by following two patterns. The results are shown in Figure 8.

1. Steer with only $12 \mathrm{~V}$ power supply.

2. Steer with $12 \mathrm{~V}$ power supply + developed system

(lithium-ion capacitor 2 cells; voltage boost $+6 \mathrm{~V}$ ).

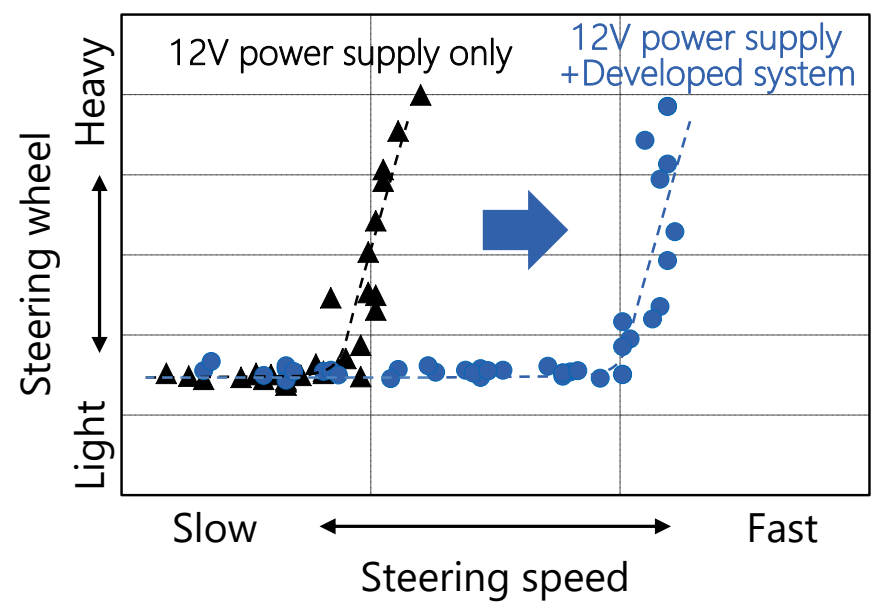

Figure 8. Comparison of torque assist responsiveness.

The $12 \mathrm{~V}$ power supply alone could not meet the EPS power demand. This caused a "torque-assist delay" that made the steering wheel heavy during high-speed steering. On the other hand, the $12 \mathrm{~V}$ power supply with the developed system experienced no torque-assist delay; the electric power shortage of the $12 \mathrm{~V}$ power supply was compensated by the electric power supplied from the lithium-ion capacitor. 
Lowering the power-assist threshold from the lithium-ion capacitor reduces the load on the $12 \mathrm{~V}$ power supply required to operate the EPS. This "peak cut function" is useful to prevent battery overload degradation in situations where some electrical components require large power demands.

Next, we compared the steering force change with the $12 \mathrm{~V}$ power supply shut down while driving with and without the development system equipped with four series-connected $500 \mathrm{~F}$ lithium-ion capacitors (total energy amount was $9600 \mathrm{~J}$ ). The results are shown in Figure 9.

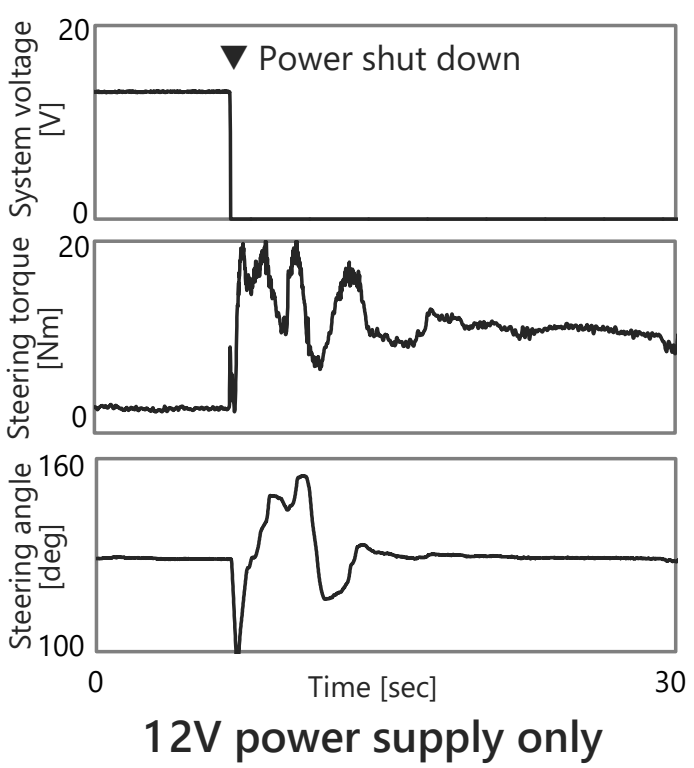

Figure 9. Comparison of steering force change when the $12 \mathrm{~V}$ power supply is shut down.

In a situation where the EPS was operated by a $12 \mathrm{~V}$ power supply alone, shutting down the $12 \mathrm{~V}$ vehicle power significantly changed the steering force and driving could not be continued. In a situation where the EPS was driven by a $12 \mathrm{~V}$ power supply and the developed system, even with the $12 \mathrm{~V}$ power supply shut down, the steering force was stable enough that the driver could not detect it.

The amount of time the developed system can sustain EPS power varies depending on the steering situation. In a steady circular turning with a radius of $10 \mathrm{~m}$, it was driven for $3 \mathrm{~min}$ or more with four lithium-ion capacitors having a capacitance of $500 \mathrm{~F}$. The reason is that, as shown in Figure 10, the backup power supply voltage can maintain $12 \mathrm{~V}$ or more. This test result is considered to be enough time for the vehicle to stop safely on the roadside after the driver detects a power failure.

In addition, in order to make it easier for the driver to notice a shutdown of the $12 \mathrm{~V}$ power supply, an EPS control was developed to gradually reduce the steering assist force. This system is suitable for autonomous vehicle required redundancy of a power supply system and is a highly safe system.

To mount the developed system with no cooling-heating device in a vehicle, the improvement of the operating temperature range of the lithium-ion capacitor was essential. Conventional capacitors have only a temperature range of about -20 to $60^{\circ} \mathrm{C}$ and cannot withstand the temperature requirement of the passenger compartment of a vehicle $\left(-40\right.$ to $\left.85^{\circ} \mathrm{C}\right)$. Since the addition of a cooling-heating device makes the system larger, heavier, less efficient, and expensive, the developed system could hardly be installed to a vehicle. As a result, JTEKT improved the operating temperature range of the lithium-ion capacitor. 


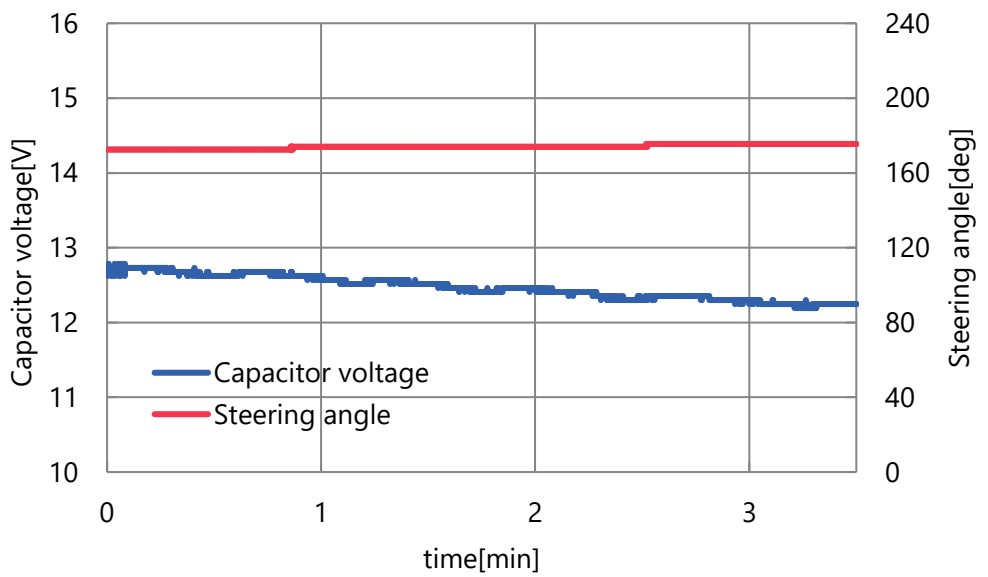

Figure 10. Capacitor voltage transition during backup power supply operation with steady circular turning (radius of $10 \mathrm{~m}$ ).

\section{Adaptation of Electrical Power Storage Device in Vehicle Environment}

\subsection{Lithium-Ion Capacitor}

The structure combines the positive electrode of an electric double layer capacitor, and the negative electrode and electrolyte solution of a lithium-ion secondary battery [14,15]. It is an electricity storage device with improved volumetric energy density that maintains the advantages of an electric double layer capacitor capable of instantaneously supplying and regenerating large amounts of power. It is expected to be used in various industries as well as automotive [16].

\subsection{Development of High-Heat-Resistant Lithium-Ion Capacitor}

Through research and testing, the phenomenon that occurs at temperatures higher and lower than the operating temperature range of conventional products was identified, and how that contributes to the deterioration of the lithium-ion capacitor performance.

With high temperature, there was an increase of internal resistance and capacitance reduction proceeded irreversibly with the thermal decomposition of the electrolyte solution. The generation of decomposition gas causes cell expansion and eventually the cell ruptures. It has been found that the decomposition of electrolyte solution is due to the thermal decomposition of lithium hexafluorophosphate $\left(\mathrm{LiPF}_{6}\right)$, which is a popular electrolyte used in lithium-ion capacitors and lithium-ion batteries.

With low temperature, output reduction with increase of internal resistance occurs reversibly. When the temperature was lowered to $-20^{\circ} \mathrm{C}$ or less, the electrolyte solution was frozen and the capacitor could not be charged/discharged. The negative electrode of a lithium-ion capacitor utilizes a chemical reaction during charge/discharge. The chemical reaction rate depends on temperature so an output reduction occurs on the low-temperature side.

From the above results, it was found that primarily an improvement of the electrolyte solution was necessary in order to extend the operating temperature range of the lithium-ion capacitor.

\section{Implementation Items}

Table 1 shows implementation items. The electrolyte salt $\mathrm{LiPF}_{6}$, which caused thermal decomposition of the electrolyte at high temperatures, was changed to high-heat-resistant lithium compound salt (imide-based lithium-compound salt). Next, the composition ratio of the electrolyte solvent was reviewed and changed to a unique carbonate-based composition that does not freeze at $-40{ }^{\circ} \mathrm{C}$ or boil at $100^{\circ} \mathrm{C}$. Furthermore, in order to make the material perform properly, we adopted our proprietary method of selecting a capacitor material based on certain chemical rules. 
Table 1. Technical challenge and implementation items.

\begin{tabular}{|c|c|c|}
\hline & Technical Challenge & Implementation Items \\
\hline \multirow{3}{*}{$\begin{array}{l}\text { Heat-resistance } \\
\text { Improvement }\end{array}$} & $\begin{array}{l}\text { Prevention of electrolyte solution } \\
\text { decomposition }\end{array}$ & $\begin{array}{l}\text { Adoption of high-heat resistance } \\
\text { electrolyte salt }\end{array}$ \\
\hline & $\begin{array}{l}\text { Prevention of electrolyte solution } \\
\text { boiling }\end{array}$ & $\begin{array}{l}\text { Adoption of high boiling-point } \\
\text { organic solvent }\end{array}$ \\
\hline & \multicolumn{2}{|c|}{ JTEKT proprietary method } \\
\hline \multirow{4}{*}{$\begin{array}{l}\text { Improvement of low } \\
\text { temperature output }\end{array}$} & \multirow{2}{*}{$\begin{array}{c}\text { Prevention of electrolyte solution } \\
\text { freezing }\end{array}$} & $\begin{array}{c}\text { Adoption of low freezing point } \\
\text { organic solvent }\end{array}$ \\
\hline & & $\begin{array}{l}\text { Optimization of organic solvent } \\
\text { mixing ratio }\end{array}$ \\
\hline & \multirow{2}{*}{$\begin{array}{l}\text { Prevention of internal resistance } \\
\text { increase }\end{array}$} & Affecter identification \\
\hline & & $\begin{array}{c}\text { Changing of positive and negative } \\
\text { materials }\end{array}$ \\
\hline
\end{tabular}

\section{Test Specimen and Testing Method}

\subsection{Test Specimen}

A sheet of activated carbon coated on aluminum foil was used as a positive electrode. A sheet of graphite coated on copper foil was used as a negative electrode. The positive electrode and the negative electrode were alternately stacked via a separator. Three types of lithium-ion capacitors (capacitance $500 \mathrm{~F}$, operating voltage 2.2 to $3.8 \mathrm{~V}$ ) shown below were prepared.

1. Conventional capacitor using electrolyte solution in which $1.0 \mathrm{~mol} / \mathrm{L}$ of $\mathrm{LiPF}_{6}$ was dissolved (ethylene carbonate (EC):ethyl methyl carbonate $(\mathrm{EMC})$ :dimethyl carbonate $(\mathrm{DMC})=3: 4: 3$ )

2. Change only electrolyte solution

3. Change electrolyte solution and JTEKT proprietary method

\subsection{Heat Resistance Evaluation}

The high-temperature endurance test of lithium-ion capacitors was based on "High temperature continuous rated voltage application test" in IEC 62813-2015: Test method for lithium ion capacitors for electrical and electronic devices-Electrical characteristics. A $3.8 \mathrm{~V}$ float charge test was conducted with an ambient temperature of $85^{\circ} \mathrm{C}$. The standard requires that the internal resistance increase rate after the float-charging test $1000 \mathrm{~h}$ is $50 \%$ or less, and the capacitance reduction ratio is required to be $20 \%$ or less.

\subsection{Evaluation of Large Current Charge-Discharge Properties}

The resistance to high current charge-discharge of the developed capacitor was investigated. The performance deterioration of the capacitor was confirmed by charge-discharge cycle test in which the maximum temperature was changed from 85 to $110{ }^{\circ} \mathrm{C}$ in steps of $5{ }^{\circ} \mathrm{C}$. The upper voltage of the capacitor was changed stepwise from 3.6 to $3.8 \mathrm{~V}$. The charge-discharge rate was $900 \mathrm{C}, \mathrm{CC} / \mathrm{CV}$ mode, and 10,000 cycles were performed.

After the cycle test, internal resistance and discharge capacity were measured according to IEC $62813-2015$, and test threshold was set to performance degradation of approximately $10 \%$ or more.

\subsection{Low-Temperature Properties Evaluation}

The internal resistance rise multiple in a low-temperature environment was investigated based on internal resistance at $25^{\circ} \mathrm{C}$. The measurement method conforms to IEC 62813-2015. 
The charge-discharge cycle performance at $-40{ }^{\circ} \mathrm{C}$ of the developed capacitor was also investigated. Capacitor voltage range was 2.2-3.8 V, CC/CV charge-discharge mode, and charge-discharge rate was $85 \mathrm{C}$. Before checking the capacitor performance, the capacitor temperature was returned to $25^{\circ} \mathrm{C}$. Internal resistance and discharge capacity were confirmed in accordance with IEC 62813-2015.

\section{Results}

\subsection{Heat Resistance Evaluation}

The results are shown in Figure 11. In the conventional capacitors, deterioration of both the capacity retention rate and internal resistance increase rate were remarkable. The required value was lowered about $100 \mathrm{~h}$ after the start of the test. The test was interrupted due to remarkable cell expansion from the decomposition of the electrolyte into gas triggered by the thermal decomposition of $\mathrm{LiPF}_{6}$ [17].

The capacitor with only the electrolyte liquid was improved in capacity retention rate and eliminated the cell expansion. However, the internal resistance increase rate was not improved.

The capacitor with electrolyte change and JTEKT proprietary method continued to meet the required values of capacity retention rate and internal resistance increase rate even after the float charge test was over the $1000 \mathrm{~h}$ specified in the standard. [18]
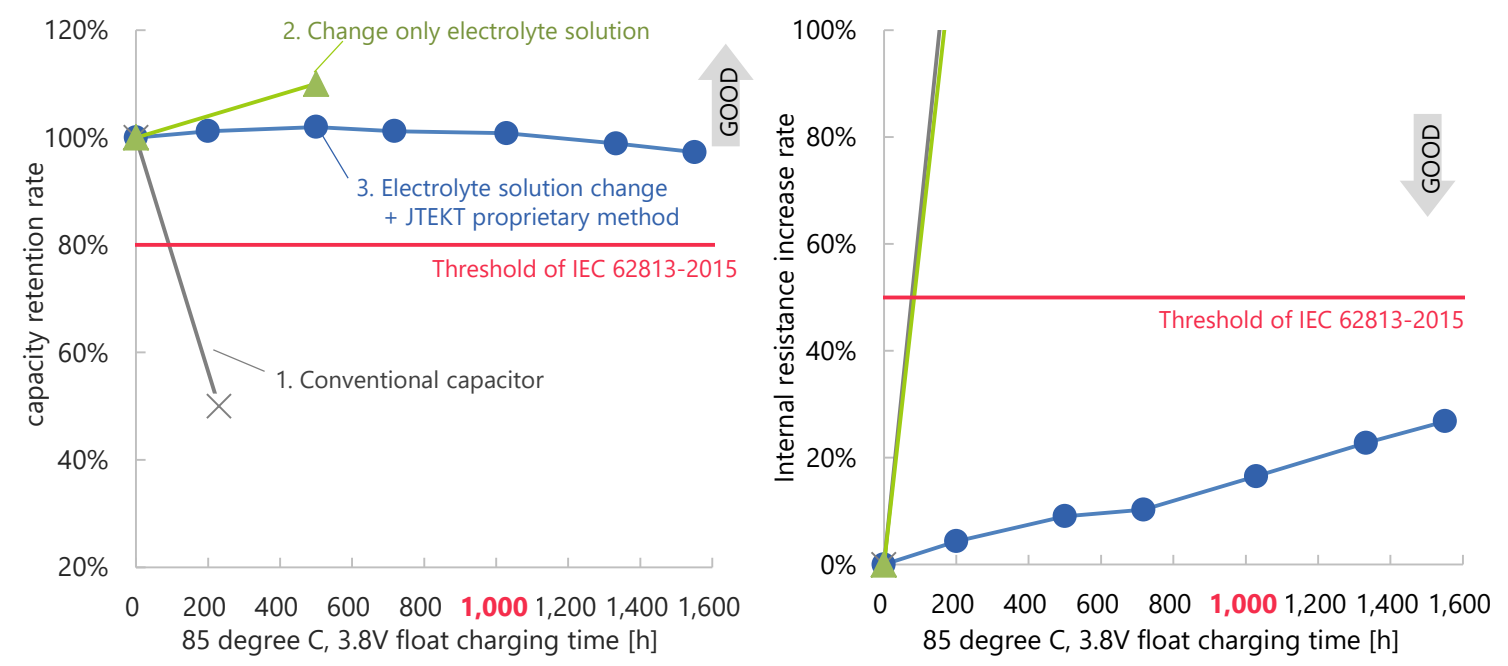

Figure 11. Test result of float charging at $85^{\circ} \mathrm{C}$ (according to IEC-62813-2015).

From the above results, in order to improve the heat resistance of the lithium-ion capacitor, it is necessary to devise not only the improvement of heat resistance of constituent materials but also the selection of material for sufficiently exhibiting the performance of each material.

\subsection{Evaluation of Large Current Charge-Discharge Properties}

The results are shown in Tables 2 and 3. By limiting upper voltage of the capacitor from $3.8 \mathrm{~V}$ to $3.6 \mathrm{~V}$, the capacitor performance hardly changed even at $100^{\circ} \mathrm{C}$. It should be noted that the improvement of heat resistance of the capacitor also contributes to suppression of deterioration due to self-heating when large current charge-discharge is repeated. 
Table 2. Internal resistance increase behavior.

\begin{tabular}{ccccccc}
\hline & & \multicolumn{5}{c}{ Upper Limit Voltage of Capacitor, V } \\
\cline { 2 - 7 } & & $\mathbf{3 . 6 0}$ & $\mathbf{3 . 6 5}$ & $\mathbf{3 . 7 0}$ & $\mathbf{3 . 7 5}$ & $\mathbf{3 . 8 0}$ \\
\hline \multirow{3}{*}{$\begin{array}{c}\text { Test atmospheric } \\
\text { temperature, } \\
\text { degree C }\end{array}$} & 110 & $24.6 \%$ & - & - & - & - \\
\cline { 2 - 7 } & 100 & $7.1 \%$ & $5.7 \%$ & - & - & - \\
\cline { 2 - 7 } & 95 & $0.3 \%$ & $2.2 \%$ & $3.7 \%$ & $5.1 \%$ & - \\
\cline { 2 - 7 } & 90 & $0.7 \%$ & $-0.2 \%$ & $3.0 \%$ & $2.1 \%$ & - \\
\hline & 85 & $0 \%$ & $2.1 \%$ & $3.5 \%$ & $3.5 \%$ & $7.7 \%$ \\
\hline
\end{tabular}

Table 3. Capacitance reduction behavior.

\begin{tabular}{ccccccc}
\hline & & \multicolumn{5}{c}{ Upper Limit Voltage of Capacitor, V } \\
\cline { 2 - 7 } & & $\mathbf{3 . 6 0}$ & $\mathbf{3 . 6 5}$ & $\mathbf{3 . 7 0}$ & $\mathbf{3 . 7 5}$ & $\mathbf{3 . 8 0}$ \\
\hline \multirow{3}{*}{$\begin{array}{c}\text { Test atmospheric } \\
\text { temperature, } \\
\text { degree C }\end{array}$} & 110 & $3 \%$ & - & - & - & - \\
\cline { 2 - 7 } & 105 & $2.3 \%$ & $-0.3 \%$ & - & - & - \\
\cline { 2 - 7 } & 95 & $0.8 \%$ & $0.5 \%$ & $0.2 \%$ & $0 \%$ & - \\
\hline & 90 & $2.0 \%$ & $0.9 \%$ & $1.4 \%$ & $0.6 \%$ & - \\
\hline & 85 & $0 \%$ & $0.8 \%$ & $0.5 \%$ & $1.4 \%$ & $0.2 \%$ \\
\hline
\end{tabular}

\subsection{Low-Temperature Properties Evaluation}

The measurement result of internal resistance is shown in Figure 12. The conventional capacitor could not be charged and discharged at $-30{ }^{\circ} \mathrm{C}$ or less due to freezing of the electrolyte solution. In contrast, the developed capacitor could be charged and discharged even at $-40{ }^{\circ} \mathrm{C}$. The internal resistance was almost the same as the conventional one at $-20^{\circ} \mathrm{C}$.

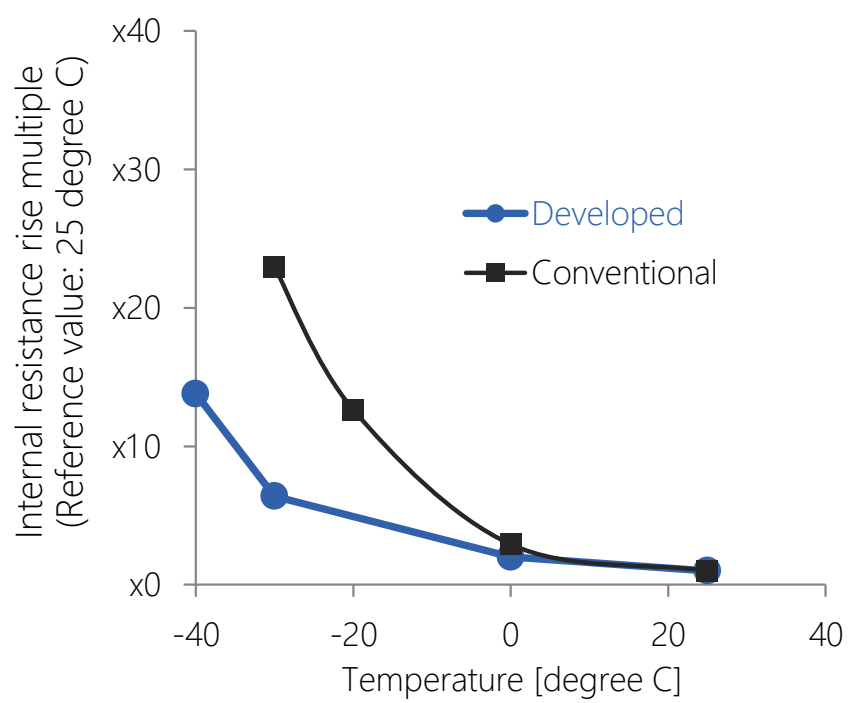

Figure 12. Measurement result of internal resistance at low temperature. 
The result of the charge-discharge cycle test at $-40{ }^{\circ} \mathrm{C}$ is shown in Figure 13. The developed capacitor showed a slight deterioration in performance even after 200,000 cycles of testing. Not only at high temperature but also at low temperature, it has been confirmed that a large current supply, which is an advantage of the capacitor, is possible.
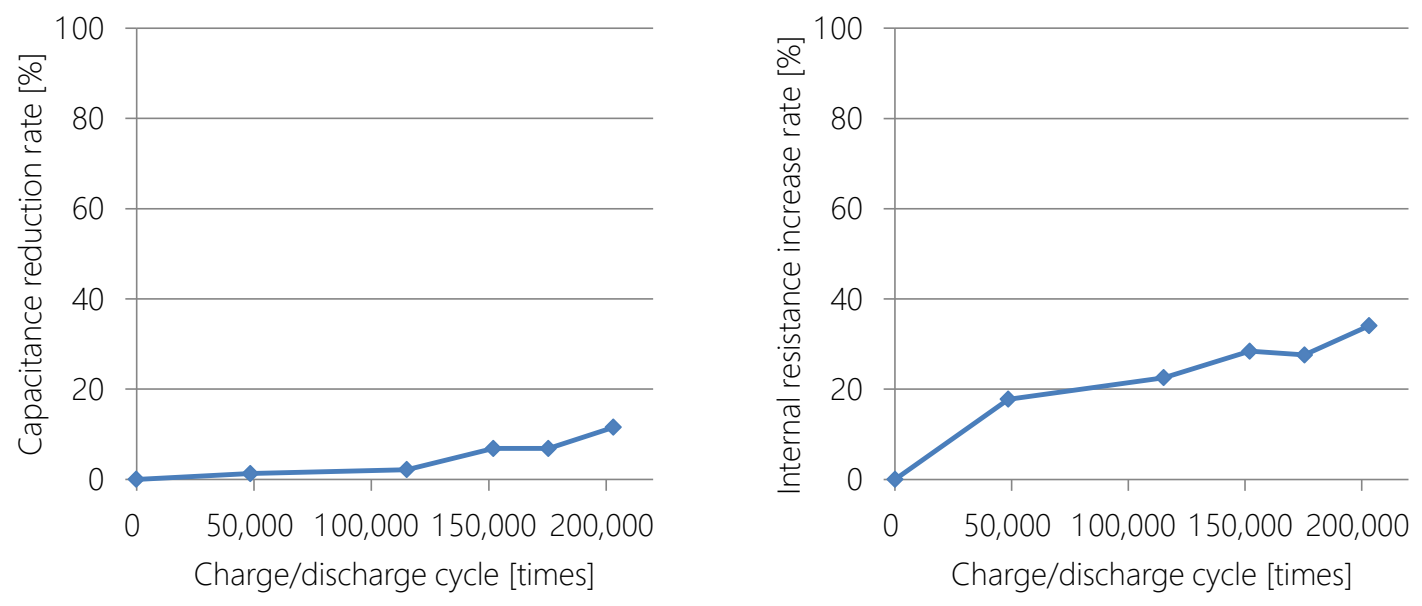

Figure 13. Test result of charge-discharge test at low temperature.

\section{Conclusions}

The newly developed auxiliary power supply system for EPS can eliminate the power shortage when mounting the EPS on a large vehicle without reinforcing the entire vehicle power supply. In addition, the developed system has excellent functional expandability, and can be operated as a redundant power supply in the event of a vehicle power failure or temporary blackout. It will support the realization of autonomous vehicles that require higher levels of safety.

In addition, the lithium-ion capacitor whose operating temperature range has been expanded helps to realize a system that can be mounted on a vehicle without a cooling-heating device. It expands the field of utilization not only in automobiles but also in various industrial fields.

Author Contributions: Data curation, K.I. and T.H.; Investigation, N.O., Y.K., K.I., F.S., and S.S.; Methodology, T.M., Y.K., Y.K., F.S., and T.H.; Project administration, T.M., T.S. (Toyoki Sugiyama), and K.N.; Software, F.S.; Supervision, K.N.; Validation, Y.K., N.O., T.S. (Tomoki Suganuma), S.M. (Shun Maruyama), and S.S.; Writing-original draft, T.M.; Writing-review \& editing, K.N.

Funding: This research received no external funding.

Conflicts of Interest: The authors declare no conflict of interest.

\section{References}

1. Japan Prime Minister's Office; Advanced Information and Telecommunications Network Society Promotion Strategy Headquarters (IT Comprehensive Strategy, Headquarters). Public-Private ITS Concept Road Map. 2018. Available online: http://www.kantei.go.jp/jp/singi/it2/kettei/pdf/20180615/siryou9.pdf (accessed on 10 May 2019).

2. SAE. Automated Driving Levels of Driving Automation are Defined in New SAE International Standard J3016. Available online: http://www.sae.org/misc/pdfs/automated_driving.pdf (accessed on 10 May 2019).

3. ISO 26262. Road Vehicles Functional Safety; ISO: Geneva, Switzerland, 2011.

4. IEC 61508-6. Functional Safety of Electrical/Electronic Programmable Electronic Safety-Related Systems, Annex B; IEC: Geneva, Switzerland, 2010.

5. Kaneko, T.; Nakamura, H.; Fukasawa, R. Safety design for Automated Driving Systems. JARI Res. J. 2016, 2016, 20161003.

6. Murata, M. Jtekt's Perspective On Steering Systems for Autonomous Driving. Automotive Mirai Summit Spring, Tokyo, Japan, 11 April 2019. 
7. Ohashi, M. 2-Drive motor control unit for electric power steering. Denso Tech. Rev. 2016, 21, 48-53.

8. Fuji Keizai Management Co., Ltd. Business Technology Office. Latest Trend of $48 \mathrm{~V}$ Conversion for Vehicle Power Supply; Fuji Marketing Report; Fuji Keizai Management Co., Ltd. Business Technology Office: Tokyo, Japan, 2014; Volume 76.

9. Miyazaki, H. Future views on EPS system technological development. JTEKT Eng. J. 2012, 1009, 19-22.

10. Shinoda, S.; Higashi, M.; Sugiyama, T. Development of Auxiliary Power Supply System for Electric Power Supply Steering. In Proceedings of the JSAE Annual Congress (Spring) Proceedings, Yokohama, Japan, 21-23 May 2014; p. 20145065.

11. Sato, F.; Higashi, M.; Sugiyama, T. Development of Auxiliary Power Supply System for Electric Power Supply Steering. In Proceedings of the JSAE Annual Congress (Spring) Proceedings, Yokohama, Japan, 20-22 May 2015; p. 20155307.

12. Hibino, T.; Sato, F.; Shinoda, S.; Sugiyama, T. Auxiliary Power Supply System for Electric Power Supply Steering. In Proceedings of the JSAE Annual Congress (Spring) Proceedings, Yokohama, Japan, 23-25 May 2018; p. 20180195.

13. Kaji, R. ISO 26262 Compliant and Redundant Design of Electric Power Steering (EPS), MONOist Automotive Forum; ISO: Geneva, Switzerland, 2015.

14. Tanizaki, H.; Matsui, K.; Tasaki, S.; Ando, N.; Hato, Y.; Shibutani, H. Development of Lithium-ion Capacitor (3). In The 47th Battery Symposium in Japan Proceedings; ESJ: Tokyo, Japan, 2006; p. 3E04.

15. Tasaki, S.; Tanisaki, H.; Miyakawa, R.; Shirakami, A.; Taguchi, H.; Matsui, K.; Ando, N.; Hatozaki, O.; Hato, Y.; Shibuya, H. Development of Lithium-ion Capacitor (4). In The 47th Battery Symposium in Japan Proceedings; ESJ: Edogawa-ku, Tokyo, Japan, 2006; p. 3E05.

16. Miyakawa, R.; Hato, Y.; Inagawa, M.; Inoue, K.; Seki, D. Development of High-Power Lithium-Ion Capacitor. NEC Tech. Rep. 2010, 63, 70-74.

17. Aurbach, D.; Zaban, A.; Ein-Eli, Y.; Weissman, I.; Chusid, O.; Markovsky, B.; Levi, M.; Levi, E.; Schechter, A.; Granot, E. Recent studies on the correlation between surface chemistry, morphology, three-dimensional structures and performance of $\mathrm{Li}$ and $\mathrm{Li}-\mathrm{C}$ intercalation anodes in several important electrolyte systems. J. Power Sources 1997, 68, 91-98. [CrossRef]

18. Takumi, M.; Komatsubara, Y.; Naoki, O.; Kimoto, Y.; Kentaro, I.; Nishi, K. Development of high heat-resistant Lithium-ion Capacitor. In Proceedings of the JSAE Annual Congress (Spring) Proceedings, Yokohama, Japan, 23-25 May 2018; p. 20180194.

(C) 2019 by the authors. Licensee MDPI, Basel, Switzerland. This article is an open access article distributed under the terms and conditions of the Creative Commons Attribution (CC BY) license (http://creativecommons.org/licenses/by/4.0/). 